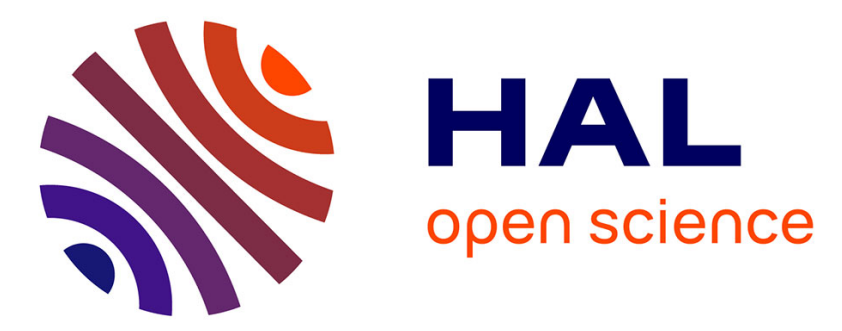

\title{
Analysis of the mechanical behaviour of materials through the 2nd and 3rd order stress determination
}

M. Belassel, V. Ji, J. Lebrun, P. Gergaud, M. François, M. Bessière

\section{To cite this version:}

M. Belassel, V. Ji, J. Lebrun, P. Gergaud, M. François, et al.. Analysis of the mechanical behaviour of materials through the 2nd and 3rd order stress determination. Journal de Physique IV Proceedings, 1994, 04 (C9), pp.C9-261-C9-264. 10.1051/jp4:1994945 . jpa-00253506

\section{HAL Id: jpa-00253506 https://hal.science/jpa-00253506}

Submitted on 1 Jan 1994

HAL is a multi-disciplinary open access archive for the deposit and dissemination of scientific research documents, whether they are published or not. The documents may come from teaching and research institutions in France or abroad, or from public or private research centers.
L'archive ouverte pluridisciplinaire HAL, est destinée au dépôt et à la diffusion de documents scientifiques de niveau recherche, publiés ou non, émanant des établissements d'enseignement et de recherche français ou étrangers, des laboratoires publics ou privés. 


\title{
Analysis of the mechanical behaviour of materials through the 2nd and 3rd order stress determination
}

\author{
M. Belassel, V. Ji, J.L. Lebrun, P. Gergaud, M. François and M. Bessière* \\ LM3, URA 1219 du CNRS, ENSAM, 151 Bd. de l'Hôpital, 75013 Paris, France \\ * LURE, Centre Universitaire de Paris-Sud, Bât. 209D, 91405 Orsay, France
}

\begin{abstract}
Based on the shift of the Bragg reflection and its broadening, 1st and 3rd order internal stresses in crystalline materials can be determined respectively by diffraction method. Between these two orders, we can define a mesoscopic scale, where the stresses come from different arrangements of dislocation arrays or grain misorientation in a polycrystal. For all materials, three orders internal stressescan be found simultaneously. The first application presented here is on an eutectoïd steel with $12 \%$ in volume of cementite. The 1 st and 2 nd order internal stresses have been determined in each phase, especially in cementite phase using a high intensity synchrotron beam. The second example concerns a cold-rolled pure Aluminum where the 2nd and 3rd order internal stresses are present at the same time. With the high resolution synchrotron diffraction, the analysis of peak asymmetry can be used to relate internal stresses with dislocation arrangements during plastic deformation.
\end{abstract}

\section{INTRODUCTION:}

Internal stresses determined by diffraction method in a two phase material are the superposition of the 1st order stress, mean stress at a macroscopic scale and the stresses between phases (2nd order), called pseudomacrostresses. For a plastic deformed single phase material, 2nd and 3rd order internal stresses will appear because of the dislocation arrays arrangements [1]. In this study, we have been interested firstly to analyse the internal stresses in each phase of a pearlitic steel (ferrite and cementite), especially in the cementite phase through the use of a very high intensity synchrotron beam; and secondly to study the internal stresses in a cold-rolled pure Aluminum by using a high resolution synchrotron beam.

\section{INTERNAL STRESSES STUDY IN A PEARLITIC STEEL}

Diffraction method for stress measurements has been applied to a pearlitic steel which contains ferrite and $12 \%$ in volume of cementite. The main difficulty in such material is related to the low amount of cementite contained in pearlite, where the intensity of diffraction peaks of orthorhombic cementite is consequently very weak, compared with those of the ferritic phase [2]. For this reason, a high intensity synchrotron radiation beam is needed. The internal stresses and the cementite behaviour have been studied for different morphologies of pearlite, i.e. globular structure and lamellar structure with different interlamellar spacings, and compared with the theoretical results obtained using a self consistent model [3] in order to understand the mechanical behaviour of the material.

\subsection{Stress Analysis Method}

As defined above, the stresses in a two phase material are 1st order at the macroscopic scale (macrostresses) and 2 nd order in the phase (pseudomacrostresses). Using the diffraction peak shifts, only the elastic strain of crystalline lattice can be determined directly in the studied direction with the use of lattice parameter as strain gauge [1]. The internal stress level is then calculated from this elastic strain with the intermediate of the X-ray elastic constants (XEC), $1 / 2 S_{2}$ and $S_{1}$. These constants can be 
determined experimentally or calculated using micromechanical models if the elastic anisotropy is known [4]. This is not the case for the cementite, its elastic properties being not yet determined.

\subsection{Experimental Procedure}

The stresses in ferrite have been studied at ENSAM using classical laboratory diffraction conditions and those in cementite at LURE Orsay (DIF4C-D23A) using synchrotron radiation. Cementite peaks are about 100 times more intense with synchrotron radiation than with classical X ray tubes. The used wavelength synchrotron radiation were 0,179 and $0,20 \mathrm{~nm}$ respectively for two series of experiments. Figures 1 and 2 show the peaks obtained, where $\{430\}$ plane has been selected for the stress analysis, because of its high diffraction angle and high intensity enables strain measurements with a good accuracy and repeatability. The XEC have been determined "in-situ" on the goniometer with the use of a four points bending device for different elastic loadings. 7 peaks at different $\psi$ angles have been used for internal stress analysis at each loading.

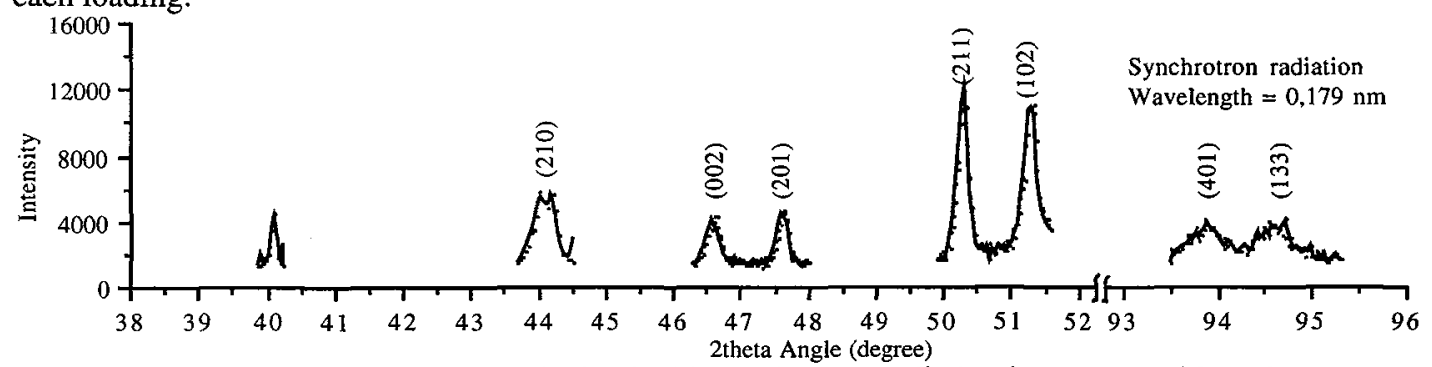

Figure 1: Cementite peaks obtained with synchrotron radiation in an eutectoid steel.

\subsection{Stress Analysis Results}

\subsubsection{X-Ray Elastic Constants}

The XEC for the $\{430\}$ plane, located at $2 \theta=129,4^{\circ}$, have been determined: $1 / 2 \mathrm{~S}_{2\{430\}}=(4,60 \pm 0,07)$ $10^{-6} \mathrm{MPa}^{-1}$ and $S_{14430\}}=(-0,63 \pm 0,21) 10^{-6} \mathrm{MPa}^{-1}$. The obtained precision is very good. Our results are consistent with those of R.A. Winholtz et al. [5] for the $\{250\}$ plane.

\subsubsection{Second Order Internal Stresses}

Figure 3 shows the internal stress evolution vs. macroscopic plastic strain obtained after tensile plastic straining and unloading in ferrite and cementite phases. Average macrostresses over the pearlite are null. In the globular cementite, the stresses increase with plastic strain till about 3\% plastic strain, and then decrease. In the ferrite, the stresses saturate at the same plastic strain. They are about $-350 \mathrm{MPa}$ in the ferrite and over $1500 \mathrm{MPa}$ in the cementite. This saturation is explained by the cementite damage due to the microstructural evolution: dislocations pile up at the interface that cause a high shear stress level leading to a fracture of the cementite [6]; and a part of elastic strains in the cementite is released. This mechanism is also observed in coarse lamellar pearlite. Simultaneously, there is an evolution of the cernentite diffraction peak width, as shown on figure 4 . We also observed that the cementite only presents elastic behaviour till 1,5\% of total strain. In this case the peak width does not increase between the initial state and the unloaded state after stressing.

For the lamellar structure, the stresses in the fine pearlite have not been determined because of the strong peak broadening caused simultaneously by elastic and plastic strains (figure 5). These results have not been stated in the literature up to now. We think that the cementite in pearlite presents a plastic behaviour when the lamellae are thin enough. Its damage has not been observed contrary to the coarse pearlite, and the internal stresses in ferrite do not saturate up to $9 \%$ of plastic strain, according to the homogeneous dislocation distribution in the ferrite [7].

\subsection{Conclusion}

These results have shown the importance of internal stress measurements to understand the mechanical behaviour of cementite in order to study the fatigue life of pearlitic steel. This was accompanied by theoretical results in a case of globular pearlite, therefore experiments with good precision are needed in order to test the modelling results. Further experiments using synchrotron radiation with wavelength variations are needed in order to analyse the elastic anisotropy of cementite by XEC determination on different planes . 


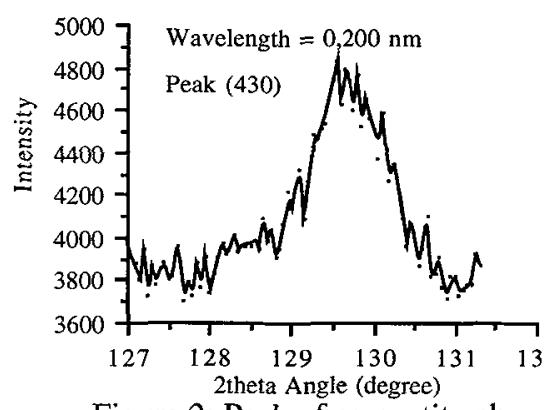

Figure 2: Peak of cementite phase

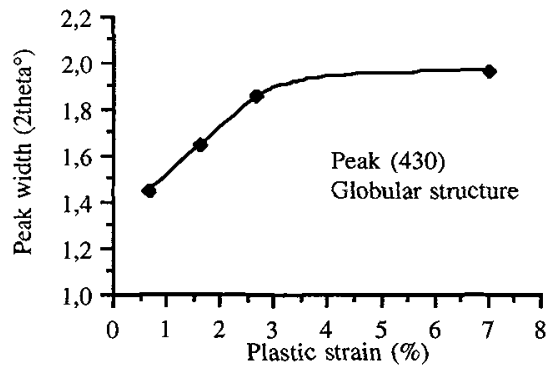

Figure 4: Peak width evolution in cementite

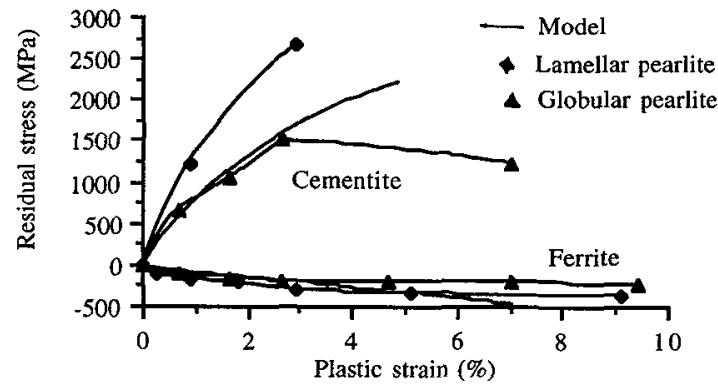

Figure 3: Experimental and modelling Stress results

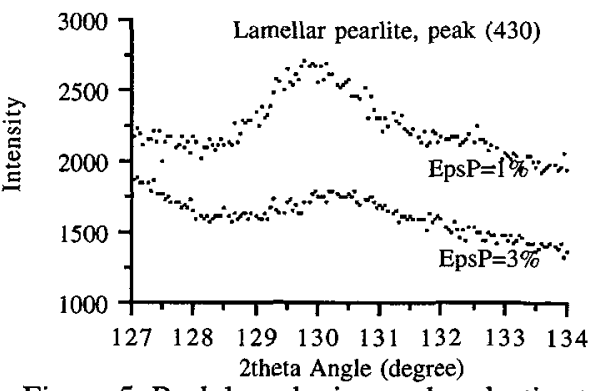

Figure 5: Peak broadening under plastic strain.

\section{INTERNAL STRESSES STUDY ON A COLD-ROLLED PURE ALUMINUM}

According to Wilkens model [8], the asymmetry of diffraction profile can be observed in the case of a cellular dislocation arrangement. This asymmetry depends on the sign and the quantity of the deformation, on the type and the orientation of Bragg reflection. It is the consequence of the dislocation distribution heterogeneity interpreted in terms of the elasto-plastic response of a two-component composite material: dislocation cell walls and cell interiors. This asymmetric profile analysis has been studied essentially on deformed monocrystalline materials. Recent works on polycrystalline samples have also shown an asymmetry of diffraction profiles [9-10]. With the large plastic deformation during coldrolling of Aluminum, a cellular dislocation microstructure formed and 2nd order internal stresses due to the interaction between the interior and wall of the cell lead to a broadening and a shift of the diffraction peaks. The analysis of the diffraction profile obtained in laboratory conditions does not permit a good separation of the effects coming from cell wall and the cell interiors [11]. With the use of a synchrotron beam, we were able to obtain a well defined asymmetry profile .

\subsection{Experimental Conditions}

A commercially pure Aluminum (99.99\%) has been used. The samples have been cold-rolled at different plastic deformation ratio $\bar{\varepsilon}$ (from 0.10 to 5.0 ). The specimens present very strong crystallographic textures after cold-rolling, of shearing type $\{100\}<011>$ beyond an equivalent deformation $\bar{\varepsilon}=0.1$. Due to the texture, though they are polycrystalline, the specimens may be analysed in a similar way to single crystals. The diffraction has been carried out on a "high resolution" goniometer in LURE Laboratory (Orsay, France) with $\lambda=0.15 \mathrm{~nm}$. A Pseudo-Voigt function has been used to fit sub-profiles coming from the cell walls and cell interiors.

\subsection{Profile Analysis Results}

An example of the analysis of profile asymmetry is presented in Figure 6. Figure 7 gives the evolution of integral peak breadth vs. equivalent plastic deformation $\bar{\varepsilon}$. The peak breadth of each sub-reflection coming from cell walls (peak 2) and cell interior (peak 1) increases rapidly in the region of low equivalent deformation, then it tends to stabilise with increasing deformation. The broadening due to dislocation cell wall is of the same order as cell interior broadening $(\approx 0.08 \mathrm{deg}$. for $\{400\}$ reflections $)$, indicating that the 3rd order internal stresses in cell wall are comparable to those in cell interior. On the other hand, 3rd order internal stresses are of the same magnitude than 2nd order internal stresses because the sub-profile shifts ( $0.5 \mathrm{deg}$. corresponding to $0.1 \%$ of elastic lattice distortion) are similar to the individual sub-profile broadening. 


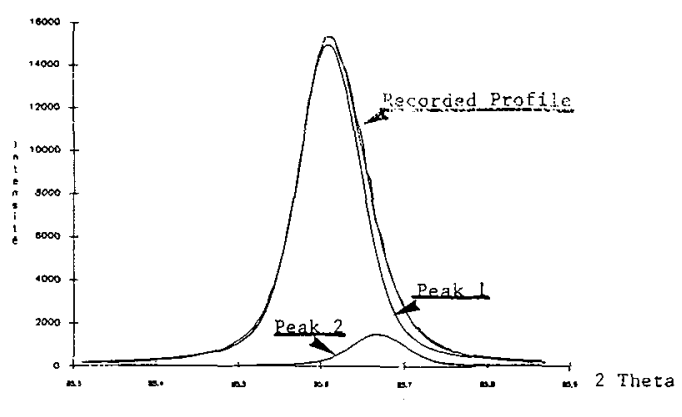

Figure 6: Example of the asymmetry peak analysis

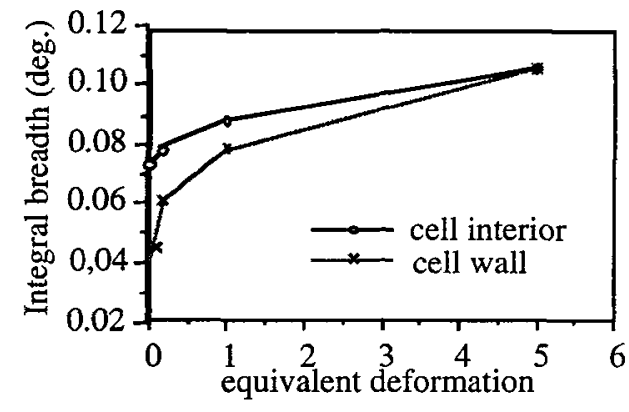

Figure 7: Peak breadth evolution vs. $\bar{\varepsilon}$.

\subsection{Discussions and Conclusions}

With the use of synchrotron diffraction setting, we observe a clear asymmetry of the profiles. It is not the case with laboratory diffraction conditions [11]. The existence of two stages of the peak breadth evolution was also observed on the same specimens by X-ray diffraction profile analysis (with laboratory conditions) and by transmission electronic microscopy (TEM) [12].

The first stage for equivalent deformation lower than $\bar{\varepsilon}_{0}$ (defined by Thang and $\mathrm{Ji}, \vec{\varepsilon}_{\mathrm{o}}$ equal to $0.1-0.5$ in our case) corresponds to progressive and homogeneous dislocation multiplication which leads to an increase of peak breadth and dislocation density, and to the continuous formation of dislocation cells. Those cells were completely structured at $\bar{\varepsilon}=\bar{\varepsilon}_{\mathrm{b}}$. As the consequence of this cold-work regime, the peak breadth in cell walls is smaller than in cell interiors because the cellular microstructure is not formed completely, and the distortion in cell walls is logically smaller than in cell interiors. Beyond $\bar{\varepsilon}_{\mathrm{o}}$, for large deformation, diffraction results indicate an increase of integral peak breadth. In this second stage of deformation, dislocations inside the cells are presumed to have a preponderant effect on the broadening of $\mathrm{X}$-ray diffraction profiles in laboratory conditions [11]. As we are able to separate the dislocation cell wall contribution and cell interior contribution, the peak breadth evolution for those two parts of material gives complementary informations: with the formation of cellular microstructure, the strain heterogeneity in cell walls becomes very important, the peak breadth becomes also important and is close to cell interior values. On the other hand, with the increase of deformation, the dislocation density tends to be stabilised dynamically, and thus the peak breadth for the two parts of the studied material has a smaller evolution than during the first stage of evolution.

We can conclude that with high resolution synchrotron diffraction technique, the recorded profile on polycrystalline aluminum enables to study the asymmetry which is difficult with laboratory conditions. Based on the Wilkens model, the 2nd and 3rd internal stresses associated with the dislocation cell wall and cell interior are analysed. The obtained high resolution profile analysis results are in good agreement with T.E.M. observations $[11,12]$.

\section{REFERENCES}

[1] J.L. Lebrun, P. Gergaud, V. Ji and M. Belassel, This conference

[2] M. Belassel, Doctorat thesis, Ecole Nationale Supérieure d'Arts et Métiers, Paris France 1994.

[3] M. Belassel, J.L. Lebrun and J.P. Bettembourg, Proceeding of ICRS4, Baltimore 1994.

[4] G. Maeder, M. Barral, J.L. Lebrun and J.M. Sprauel, The Rigaku Journal, Vol.3, N² (1986) 9-20.

[5] R.A. Winholtz and J.B. Cohen, Metallurgical Transaction A, 23, 341 (1992)

[6] D.A. Porter, K.E. Easterling et G.D.W. Smith, Acta Metallurgica, 26, 1405 (1978)

[7] N. Ji, J.L. Lebrun and H.P. Lieurade, Mécanique Matériaux Electricité, 43, 32 (1990)

[8] M.Wilkens, Phys. Stat. Sol., 2(a), 359 (1970)

[9] H. Biermann, T. Ungar, T. Pfannenmuller, G. Hoffmann, A. Borbely and H. Mughrabi, Acta metallurgica, 41, 2743 (1993)

[10] A. Borbely, H.J. Maier, H. Renner, S. Straub, T. Ungar and W. Blum, Scripta metall., 29, 7 (1993)

[11] N. Ji, J.L. Lebrun and P. Sainfort, Journal of Materials Science, 29, 1553 (1994)

[12] T.Q. Thang, Doctorat Thesis, Institut National Polytechnique de Grenoble, France 1986. 